\title{
In vitro analysis of different properties of acrylic resins for ocular prosthesis submitted to accelerated aging with or without photopolymerized glaze
}

\author{
Daniela Micheline dos Santos ${ }^{\mathrm{a}, *}$, Bruna Egumi Nagay ${ }^{\mathrm{a}}$, Emily Vivianne Freitas da Silva ${ }^{\mathrm{a}}$, \\ Liliane da Rocha Bonatto ${ }^{\mathrm{a}}$, Mariana Vilela Sonego ${ }^{\mathrm{a}}$, Amália Moreno ${ }^{\mathrm{b}}$, Elidiane Cipriano Rangel ${ }^{\mathrm{c}}$, \\ Nilson Cristino da Cruz ${ }^{\mathrm{c}}$, Marcelo Coelho Goiato ${ }^{\mathrm{a}}$ \\ a Department of Dental Materials and Prosthodontics, Aracatuba Dental School, Sao Paulo State University (UNESP), Aracatuba, Sao Paulo, Brazil \\ b Department of Oral Surgery and Pathology, School of Dentistry, Federal University of Minas Gerais (UFMG), Belo Horizonte, Minas Gerais, Brazil \\ c Technological Plasma Laboratory (LaPTec), Experimental Campus of Sorocaba, UNESP, Sorocaba, Sao Paulo, Brazil
}

\section{A R T I C L E I N F O}

\section{Article history:}

Received 9 June 2016

Received in revised form 22 July 2016

Accepted 31 July 2016

Available online 2 August 2016

\section{Keywords:}

Artificial eye

Acrylic resins

Hardness

Color

Surface properties

\begin{abstract}
A B S T R A C T
The effect of a photopolymerized glaze on different properties of acrylic resin (AR) for ocular prostheses submitted to accelerated aging was investigated. Forty discs were divided into 4 groups: N1 AR without glaze (G1); colorless AR without glaze (G2); N1 AR with glaze (G3); and colorless AR with glaze (G4). All samples were polished with sandpaper (240, 600 and 800 -grit). In G1 and G2, a 1200-grit sandpaper was also used. In G3 and G4, samples were coated with MegaSeal glaze. Property analysis of color stability, microhardness, roughness, and surface energy, and assays of atomic force microscopy, scanning electron microscopy, and energy-dispersive spectroscopy were performed before and after the accelerated aging (1008 $\mathrm{h}$ ). Data were submitted to the ANOVA and Tukey Test $(p<0.05)$. Groups with glaze exhibited statistically higher color change and roughness after aging. The surface microhardness significantly decreased in groups with glaze and increased in groups without glaze. The surface energy increased after the aging, independent of the polishing procedure. All groups showed an increase of surface irregularities. Photopolymerized glaze is an inadequate surface treatment for AR for ocular prostheses and it affected the color stability, roughness, and microhardness. The accelerated aging interfered negatively with the properties of resins.
\end{abstract}

C 2016 Elsevier B.V. All rights reserved.

\section{Introduction}

Colorless and N1 acrylic resins are the materials of choice for the fabrication of ocular prostheses since they exhibit easy handling, good adaptation, satisfactory esthetics, and low cost [1-3]. N1 acrylic resin simulates the natural color of the sclera, while colorless resin is used to cover the characterization of blood vessels and artificial iris [2-5]. To ensure longevity of an ocular prosthesis, it is essential to ensure its esthetic, chemical, physical, and mechanical properties [1,6,7].

Regarding esthetics, color stability is the property a material possesses to stably maintain its color for a period of time, in a specific environment [8]. Material discoloration may be caused by intrinsic or extrinsic factors [9]. Concerning intrinsic factors, the change of the

\footnotetext{
* Corresponding author at: Department of Dental Materials and Prosthodontics, Aracatuba Dental School, Sao Paulo State University - UNESP, Jose Bonifacio St., 1153, Vila Mendonca, Aracatuba, Sao Paulo, Brazil.

E-mail address: danielamicheline@foa.unesp.br (D.M. Santos).
}

resin color results from matrix alteration during aging, due to physical and chemical conditions [9-12], while the extrinsic factors include solar radiation, temperature and humidity changes, absorption and adsorption of substances $[6,13,14]$.

Acrylic resin consists of a polymer powder of methyl methacrylate and a liquid methyl methacrylate monomer, which has excellent endurance, and regarding its polymerization, can be thermoactivated by microwave energy, heated water, or autopolymerized [15]. The chemical composition can be evaluated by an analysis of energydispersive spectroscopy (EDS), which identifies the concentration of chemical elements from the surface of a specimen [16].

Regarding the physical and mechanical properties, surface hardness of a material is defined by the resistance to permanent penetration [6]. When it is reduced, it results in scratches, cracks, and fractures in the restoration $[9,17,18]$. Interestingly, the occurrence of fractures is one of the factors that interferes in rehabilitation treatment maintenance $[4,6]$, since fractures result in surface irregularities, patient discomfort, and irritation [4]. Furthermore, the smoothness of the resin surface 
hinders bacterial adhesion, which is essential [19-21], since bacteria are better protected on rough surfaces and have the necessary conditions to achieve a direct contact with the prosthesis surface $[4,17]$.

The mechanical or chemical polishing procedures of acrylic resin aim to reduce the prosthesis surface roughness, and consequently, the accumulation of impurities and microorganisms [22]. Mechanical polishing is performed with felt wheels and rotating soft brushes associated with polishing pastes. Chemical polishing consists of immersing the acrylic resin in a warm monomer for $1 \mathrm{~min}$ to obtain a surface smoothness $[22,23]$. Although literature is sparse on this issue, the application of a glaze (photopolymerized sealant) has been reported in order to ensure the surface smoothness of ceramic [24], acrylic resin provisional restorations [25], and dentures [26], thus avoiding the accumulation of biofilm and bacterial colonization [26,27].

The knowledge of the topographic characteristics of a material surface can be given through the scanning electron microscopy (SEM), which microscopically analyzes the overall structure of the material [28]. The surface roughness can be analyzed by atomic force microscopy, which provides detailed and high-quality three-dimensional resolution images [29].

The mechanical polishing is performed in stages, and requires diligence and care in all steps, aiming for the obtainment of a smooth surface [22]. However, the photopolymerized glaze can reduce the cost and the duration of manufacturing of the prosthesis, since less grit sizes are required. In addition, there is a growing importance regarding the longevity and durability of ocular prosthesis materials, and their consequent impact on the quality of life of anophthalmic patients. Therefore, this study aimed to evaluate different properties of ocular prosthesis acrylic resin subjected to accelerated aging, with mechanical polishing or after photopolymerized glaze application. The null hypothesis is that the photopolymerized glaze does not interfere in the properties of ocular prosthesis acrylic resin.

\section{Materials and methods}

\subsection{Sample preparation}

Forty specimens of N1 $(n=20)$ and colorless $(n=20)$ acrylic resins (Table 1) were manufactured using a metallic matrix containing 10 circular compartments with $10 \mathrm{~mm}$ in diameter and $3 \mathrm{~mm}$ in thickness [30]. This device was embedded with type IV dental stone (Durone, Dentsply Ind e Com Ltda, Rio de Janeiro, Brazil) in a flask specific for microwave energy (Classico Dental Products, Sao Paulo, Brazil).

The N1 acrylic resin was mixed according to the instructions of the manufacturer. After the resin insertion into the matrix, a counter-flask was positioned and raised in a hydraulic bench press with a $1.250 \mathrm{kgf}$ weight for $3 \mathrm{~min}$. After a bench polymerization for $30 \mathrm{~min}$ [6], the resin was polymerized by microwave energy (Brastemp, Sao Paulo, Brazil), according to the recommendations of the manufacturer. After resin polymerization, the specimen excess was removed with a Maxi-Cut abrasive drill (Vicking, Sao Paulo, Brazil).

The specimens were divided into 4 groups $(n=10)$ : N1 acrylic resin without photopolymerized glaze (G1); colorless acrylic resin without photopolymerized glaze (G2); N1 acrylic resin with photopolymerized glaze (G3); and colorless acrylic resin with photopolymerized glaze (G4).

The specimens were polished in an automated polishing machine (Ecomet 300PRO Buehler, Illinois, USA), with sandpaper of different granulations (240,600, and 800-grit), under constant water irrigation at $300 \mathrm{rpm}$ [31]. Additionally, in G1 and G2, a 1200-grit sandpaper was also used and the specimens were finalized with a diamond solution with a felt disk (Buehler, Illinois, USA). To ensure the proposed dimensions, each specimen thickness was measured using a precision digital caliper (500-171-20B, Tokyo, Japan). Equal procedures were performed for the preparation of colorless acrylic resin specimens. In G3 and G4, specimens were coated with MegaSeal (Megadenta, Saxony, Germany) photopolymerized glaze (Table 1), according to the instructions of the manufacturer. The photopolymerization was performed for $180 \mathrm{~s}$ with the Strobolux system (EDG Equipment, Sao Paulo, Brazil).

Analyses of properties in relation to color stability, microhardness, roughness, and surface energy were performed. Also, assays of atomic force microscopy (AFM), scanning electron microscopy (SEM), and energy-dispersive spectroscopy (EDS) were performed before and after the accelerated aging of the specimens.

\subsection{Color analysis}

Color changes $(\Delta \mathrm{E})$ were analyzed by refraction spectrophotometry (UV-2450, Shimadzu Corp., Kyoto, Japan) and calculated using the CIE $\mathrm{L} * \mathrm{a} * \mathrm{~b}$ system, as established by the International Commission on Illumination (CIE) [32], considering the color perception between two points in a three-dimensional color space $[5,25,31,33]$.

\subsection{Microhardness analysis}

The Knoop surface microhardness was analyzed with a microdurometer (HMV-2T model, Shimadzu Corp., Kyoto, Japan), following ASTM (American Society for Testing Materials) specifications [34], with a $25 \mathrm{~g}$ load for $10 \mathrm{~s}$ [6,35]. Each specimen was submitted to five penetrations, respecting a distance of $500 \mu \mathrm{m}$ between penetrations and from the specimen boards [36].

\subsection{Surface roughness}

The roughness was analyzed by profilometry analysis and AFM. The first analysis was performed using a profilometer (Dektak D-150, Veeco, New York, USA), on the specimen side opposite of where the microhardness evaluation was performed. The profilometer needle was positioned on the specimen surface, which was individually placed in the center of the equipment [2,37]. The Rt (total height of roughness profile) values were measured using a cutoff of $500 \mu \mathrm{m}$ during $12 \mathrm{~s}$. Three readings were performed on each specimen surface and the average was calculated.

\subsection{Atomic force microscopy}

AFM was used to study surface morphology of one additional specimen of each group. The images were transported from a microscope (Veeco Metrology Inc., California, USA) to a computer, and the images were submitted to filters ("lowpass" and "medium") in a NanoScope Analysis program (2004 Veeco Instruments Inc., California, USA). Three-dimensional images were standardized to a scale of the z-axis for further qualitative comparison between groups [37].

Table 1

Material, manufacturer, and chemical composition of materials used in study.

\begin{tabular}{|c|c|c|}
\hline Material & Manufacturer & Chemical composition \\
\hline Acrylic resin polymer & Artigos Odontológicos Clássico Ltda, Sao Paulo, Brazil & Methyl-methacrylate (MMA) polymer, dibutyl phthalate, ethyl acrylate, pigments \\
\hline Monomer & Onda Cryl, Artigos Odontológicos Clássico Ltda, Sao Paulo, Brazil & Microwave polymerization: MMA monomer, topanol, Ethylene glycol dimethacrylate \\
\hline Photopolymerized glaze & Mega Seal, Megadenta, Radeberg, Germany & MMA, dimethacrylate, photochemical initiators, stabilizers \\
\hline
\end{tabular}


Table 2

Mean values and standard deviation of color change $(\Delta E)$ for each resin evaluated.

\begin{tabular}{lll}
\hline & \multicolumn{2}{c}{ Treatment } \\
\cline { 2 - 3 } Resins & $\frac{\text { Without glaze }}{\Delta \mathrm{E}}$ & $\frac{\text { With glaze }}{\Delta \mathrm{E}}$ \\
\cline { 2 - 3 } Colorless resin & $3.54(2.11)$ & $4.83(2.98)$ \\
N1 resin & $7.44(1.53)$ & $11.27(2.94)$ \\
\hline
\end{tabular}

\subsection{Surface energy}

The degree of wettability was examined by using the surface energy test on all samples of each group, employing the sessile drop method at a controlled temperature [38]. Twenty readings were made for each specimen, with ten readings to determine the deionized water contact angle (polar component), and ten readings to measure the diiodomethane contact angle (dispersive component). A goniometer (Ramé-Hart 100-00, Ramé-Hart Instrument Co., New Jersey, USA) was used, associated with software (DROPimage Standard, Ramé-Hart Instrument Co., New Jersey, USA), to measure the surface energy. The calculation of surface energy was performed according to the OwensWendt-Rabel-Kaelble (OWRK) method [39].

\subsection{SEM-EDS}

One additional specimen of each group was used to characterize the surface by scanning electron microscopy (SEM) (JSM 610LA, JEOL, Tokyo, Japan). Representative images were recorded with $\times 10.000$ magnification. Then, qualitative comparison of images was performed between groups. Energy dispersive spectroscopy (EDS) evaluation was performed on small volumes, on the order of $1 \mu \mathrm{m}^{3}$, to identify the chemical elements presented on the specimen surface.

\subsection{Accelerated aging}

After initial readings and analysis, the specimens were submitted to accelerated aging in an accelerated aging chamber for non-metallic bodies (Comexim Raw Materials Ind. Com. Ltda., Sao Paulo, Brazil), according to ASTM G53 [40]. The specimens were exposed to $1008 \mathrm{~h}$ of accelerated aging [6,31]. After this period, new readings of the above tests were performed.

\subsection{Statistical analysis}

The quantitative data of the analysis of color stability, microhardness, roughness, and surface energy were submitted to the analysis of variance (ANOVA) and Tukey Test at $5 \%$ significance. Qualitative data of the analysis of AFM, surface energy, and SEM/EDS were visually compared.

\section{Results}

All groups presented color change $(\Delta \mathrm{E}>0)$ after accelerated aging, regardless of the type of polishing $(d f=1 ; F=10.813 ; P=0.002)$
Table 4

Mean values and standard deviation of resin surface roughness (Rt) for each treatment and period evaluated, independent of acrylic resin.

\begin{tabular}{lll}
\hline & Period & \\
\cline { 2 - 2 } Treatment & Initial & Final \\
\cline { 2 - 3 } & $\mathrm{Rt}$ & $\mathrm{Rt}$ \\
\hline Without glaze & $0.197(0.062) \mathrm{Aa}$ & $0.156(0.060) \mathrm{Aa}$ \\
With glaze & $0.186(0.046) \mathrm{Ab}$ & $1.540(0.567) \mathrm{Ba}$ \\
\hline
\end{tabular}

Means followed by same capital letter in column do not differ $(P<0.05$, Tukey). Means followed by same lowercase letter in line do not differ $(P<0.05$, Tukey).

and resin used $(d f=1 ; \mathrm{F}=44.094 ; P<0.0001)$ (Tables 2 and 3$)$. In addition, it was observed that groups with glaze showed higher $\Delta \mathrm{E}$ than groups with mechanical polishing, with a statistically significant result (Table 3).

Regarding the roughness analysis, statistically significant differences were observed in the interaction between two factors (period $\mathrm{x}$ treatment) $(d f=1 ; \mathrm{F}=111.160 ; P<0.0001)$ (Tables 4 and 5$)$. The groups with glaze exhibited the highest roughness values after aging, regardless of the acrylic resin (Table 4). Moreover, N1 acrylic resin groups showed statistically higher Rt values than colorless resin groups (Table 5).

Through the representative images of AFM before accelerated aging (Fig. 1), greater surface irregularities were observed for $\mathrm{N} 1$ acrylic resin groups without glaze, when compared to other groups. However, through AFM images after accelerated aging, an increase of irregularities was verified for all groups, indicating that aging has an adverse effect on the surface smoothness. Additionally, N1 resins with glaze showed the most irregular surfaces, after accelerated aging.

When evaluating the surface microhardness, a statistically significant difference was verified in the interaction of three factors (period $\mathrm{x}$ treatment $\mathrm{x}$ resin $)(\mathrm{df}=2 ; \mathrm{F}=50.890 ; P<0.0001)$. Concerning the acrylic resin type in groups with chemical polishing, the highest microhardness values were observed for colorless resins, with statistical difference, regardless of the tested period (Table 6). Additionally, the surface microhardness values decreased in groups with chemical polishing after aging, whereas it increased in groups with mechanical polishing. In colorless acrylic resins with photopolymerized glaze, the microhardness increased significantly after aging. The N1 resins with glaze exhibited higher microhardness values than other groups before aging (Table 6).

In the surface energy analysis, statistically significant differences were observed in the interaction between two factors (period $\mathrm{x}$ resin) $(d f=1 ; F=6.073 ; P=0.016)$. Statistical difference was observed in the degree of wettability for N1 resins, when comparing periods before and after aging (Table 7). Through Fig. 2, it was observed that the configurations formed by drops of deionized water deposited on the surface of acrylic resin specimens were similar for all groups.

Through representative SEM images with $\times 10.000$ magnification (Fig. 3), an increase of irregularities was verified after aging, when compared to groups before aging, especially in groups with glaze (G1 and G2). Regarding the chemical composition of the near-surface region observed through EDS evaluation (Fig. 4), the presence of carbon (C) and oxygen $(\mathrm{O})$ was detected for all groups.
Table 3

Mean values and standard deviation of color change $(\Delta E)$ for each surface treatment, independent of acrylic resin.

\begin{tabular}{ll}
\hline Treatment & $\Delta \mathrm{E}$ \\
\hline Without glaze & $5.49(2.69) \mathrm{A}$ \\
With glaze & $8.05(4.38) \mathrm{B}$ \\
\hline Means followed by same capital letter in column do not differ \\
$(P<0.05$, Tukey).
\end{tabular}

Table 5

Mean values and standard deviation of surface roughness (Rt) for each resin evaluated, independent of treatment and period.

\begin{tabular}{ll}
\hline Resins & $\mathrm{Rt}$ \\
\hline Colorless resin & $0.453(0.570) \mathrm{A}$ \\
$\mathrm{N} 1$ resin & $0.587(0.734) \mathrm{B}$ \\
\hline Means followed by same capital letter in column do not differ
\end{tabular}

$(\mathrm{P}<0.05$, Tukey) 
A

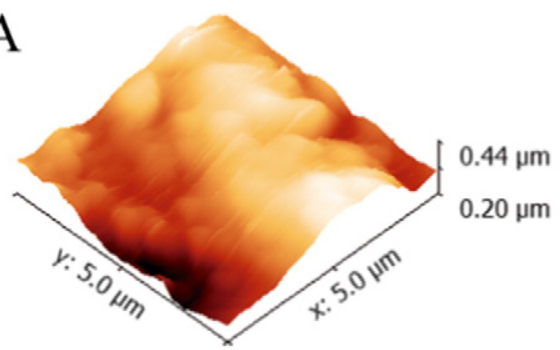

$\mathrm{C}$

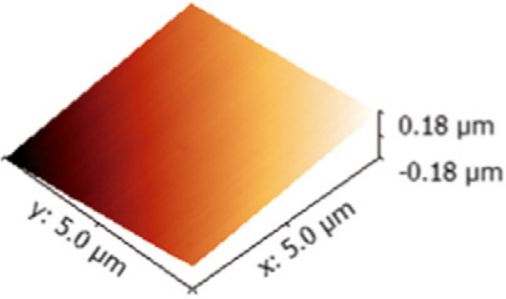

E

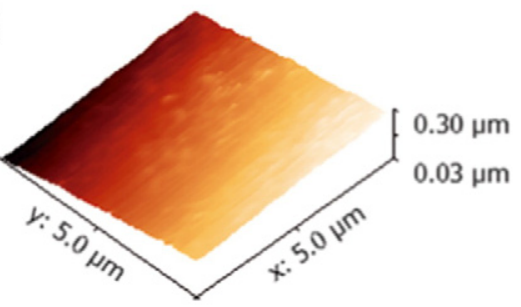

G

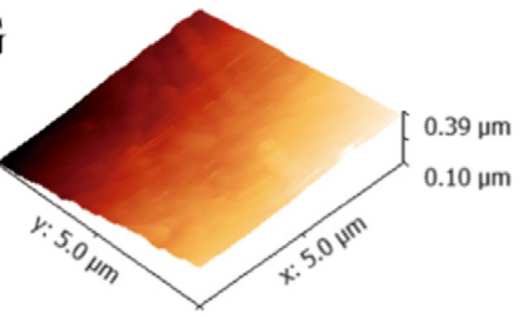

B

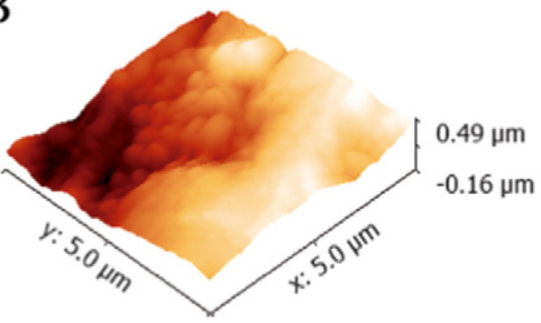

$\mathrm{D}$

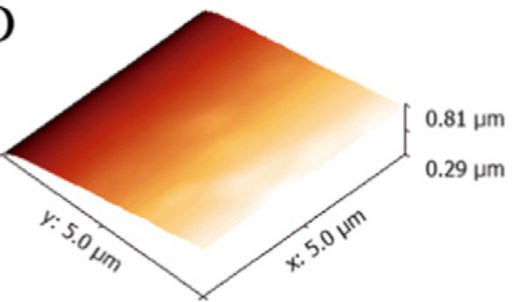

F
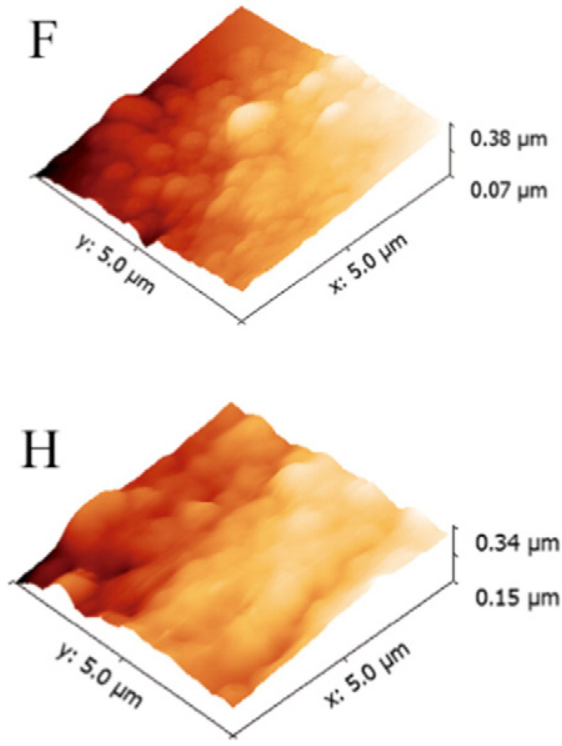

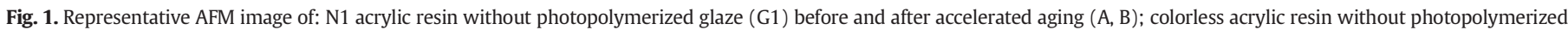

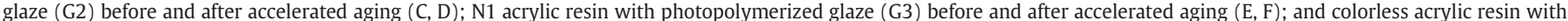
photopolymerized glaze (G4) before and after accelerated aging $(G, H)$.

\section{Discussion}

The null hypothesis tested in this study, that the photopolymerized glaze does not interfere in the properties of ocular prosthesis acrylic resin, was not accepted since color stability values $(\Delta \mathrm{E})$ were higher in groups with glaze (Table 3 ). Regarding surface microhardness, groups with glaze had a reduction in microhardness after accelerated aging (Table 6). Moreover, the roughness of these groups was greater after aging, when compared to groups with mechanical polishing (Table 4).
In this study, $\Delta \mathrm{E}$ values increased after aging for all groups, indicating color alteration of the material tested (Table 2). This color change can be caused by extrinsic and intrinsic factors [6,9-11,13,14]. According to Goiato et al. (2010) [22], factors such as ultraviolet light, heat, and humidity, which are present during the accelerated aging process, are responsible for polymer degradation. Ultraviolet light is absorbed by functional groups of polymer chains present in most polymers. When this happens, a dispersion of excess energy can occur, with consequent photochemical degradation, which contributes to a surface

Table 6

Mean values and standard deviation of microhardness for each resin, treatment, and period evaluated.

\begin{tabular}{|c|c|c|c|c|}
\hline \multirow[t]{3}{*}{ Resins } & \multicolumn{4}{|l|}{ Treatment } \\
\hline & \multicolumn{2}{|l|}{ Without glaze } & \multicolumn{2}{|l|}{ With glaze } \\
\hline & Initial & Final & Initial & Final \\
\hline Colorless resin & $19.50(0.44) \mathrm{Aa}$ & $21.31(1.12) \mathrm{Ab}$ & $36.10(0.80)$ Ac & 25.51 (1.68) Ad \\
\hline N1 resin & $21.06(0.66) \mathrm{Aa}$ & $22.76(2.41) \mathrm{Aa}$ & 32.76 (1.69) Bb & $21.70(0.72) \mathrm{Ba}$ \\
\hline
\end{tabular}

Means followed by same capital letter in column do not differ $(P<0.05$, Tukey). Means followed by same lowercase letter in line do not differ ( $<<0.05$, Tukey). 
Table 7

Mean values and standard deviation of surface energy for each resin evaluated before and after aging, independent of treatment.

\begin{tabular}{lll}
\hline \multirow{2}{*}{ Resins } & Period & \\
\cline { 2 - 3 } & Initial & Final \\
\cline { 2 - 3 } & ES & ES \\
\hline Colorless resin & $44.90(3.26) \mathrm{Aa}$ & $46.05(5.15) \mathrm{Aa}$ \\
N1 resin & $40.85(5.03) \mathrm{Aa}$ & $46.74(5.60) \mathrm{Ab}$ \\
\hline
\end{tabular}

Means followed by same capital letter in column do not differ $(P<0.05$, Tukey). Means followed by same lowercase letter in line do not differ $(P<0.05$, Tukey).

deterioration, such as the appearance of cracks and loss of color or brightness [22].

There is still controversy regarding the establishment of a satisfactory clinical value for color change. Canadas et al. (2010) [15], Goiato et al. (2010) [31] and, Mundim et al. (2012) [41] affirm that $\Delta \mathrm{E}$ values $>3.3$ are clinically unacceptable, while other authors state that this value must be $>3.7$ [5]. In this study, all groups had visually perceptible color change, and groups with photopolymerized glaze were the most clinically unacceptable (Tables 2 and 3 ). According to Rutkunas et al. (2010) [25], although the glaze increases the resistance to coloration by reducing the surface porosity, its retention on the surface of the acrylic resin may be lost over time [25]. This appears to have occurred in this study after the accelerated aging.

Color changes can be associated with the accumulation of impurities and are influenced by acrylic resin chemical composition and surface characteristics, such as roughness $[22,42,43]$. The porosity of acrylic resins may result from factors such as exposure to water during material handling and inadequate polymerization conditions, such as monomer contraction during polymerization and the presence of residual monomer. As a result, there is physical and esthetic damage to the material $[15,44,45]$. Therefore, the material color stability increases when reducing the surface porosity [25].

Surface roughness of the material depends on the finishing and polishing, and the presence of microporosities [2]. Therefore, the surface roughness parameter (Rt) was evaluated in order to clarify if the application of glaze can or cannot influence the acrylic resin structural

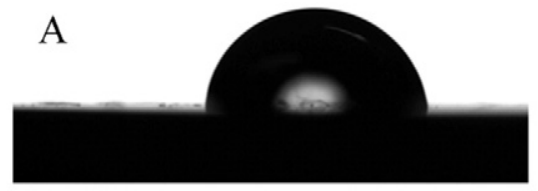

C

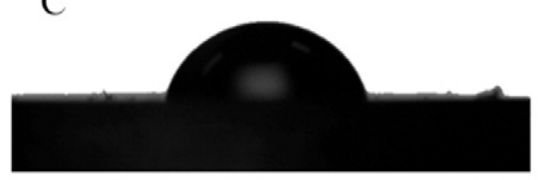

$\mathrm{E}$

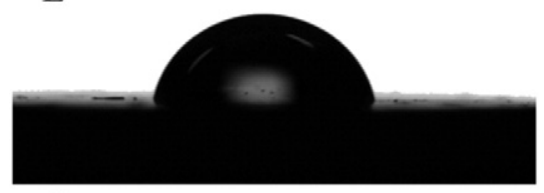

G

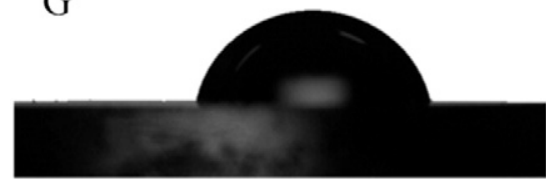

characteristics. According to Rutkunas et al. (2010) [25], the glaze aims to regularize the material surface. However, it was observed that groups with glaze (G3 and G4) showed the highest values of Rt after aging (Table 4) in the present study. This may have occurred due to aging effects, which could cause surface glaze degradation $[4,22,25]$.

In the present study, the Rt values were greater for N1 resin, when compared to colorless resin, with statistical difference (Table 5), and a higher surface irregularity was observed for N1 resin with glaze, through AFM (Fig. 1). Possibly, this is related to the presence of pigments and the higher molecular weight of this resin $[2,3,6]$.

It is stated that the acrylic resin used in an ocular prosthesis does not present an irregular surface, aiming to prevent bacterial proliferation, damage to underlying tissue, and irritation of the patient anophthalmic cavity $[15,22]$. However, an ocular prosthesis is often exposed to temperature variations, degradation, and cleaning by the patient. Thus, the colorless acrylic resin can acquire a scratched surface, damaging the esthetic aspect and surface smoothness [1].

The longevity of ocular prostheses is directly related to the surface hardness of the acrylic resin. Greater microhardness values are associated with a higher resistance to abrasive wear $[1,4,18]$. After accelerated aging, groups with glaze exhibited higher microhardness values than groups with mechanical polishing, with statistically significant difference (Table 6). These results differ from the study of Braun et al. (2003) [23], which found that the chemical polishing of acrylic resins with heated monomer, when compared to mechanical polishing, generates lower hardness values [23].

Due to the water absorption and the increase of temperature that resins suffer during the accelerated aging process, the release of residual monomer can increase, leading to a continuous polymerization of the resin, and consequently, greater microhardness values [1]. The values of the present study (Table 6 ) are clinically acceptable, since according to the American Dental Association (ADA), the microhardness of acrylic resin used for artificial teeth should not be $<15 \mathrm{~kg} / \mathrm{mm}$ [46]. Furthermore, according to Fernandes et al. (2009) [1], the microhardness of thermoactivated acrylic resin should be between 16 and $22 \mathrm{~kg} / \mathrm{mm}$. Higher microhardness values decrease the probability of cracks occurring and increase the scratch resistance, reducing possible microbial colonization and future infections [1].

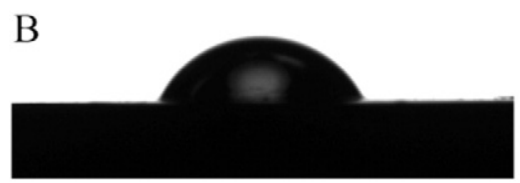

D

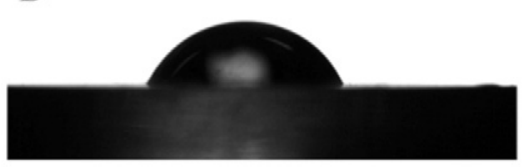

F

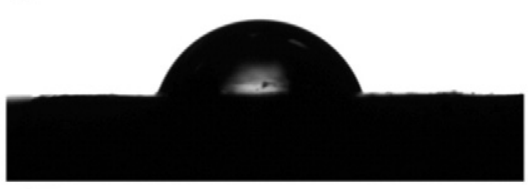

$\mathrm{H}$

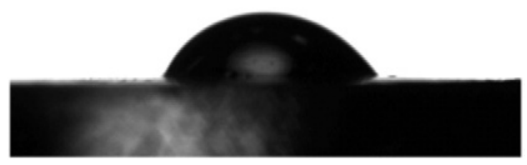

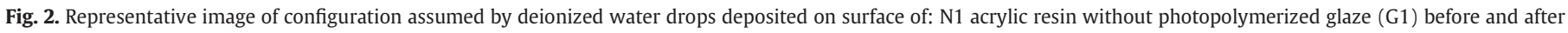

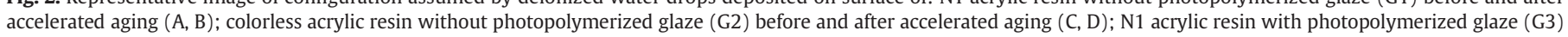
before and after accelerated aging (E, F); and colorless acrylic resin with photopolymerized glaze (G4) before and after accelerated aging ( $\mathrm{G}, \mathrm{H}$ ). 
A

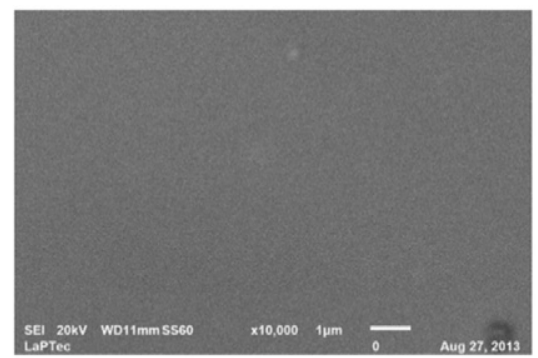

C

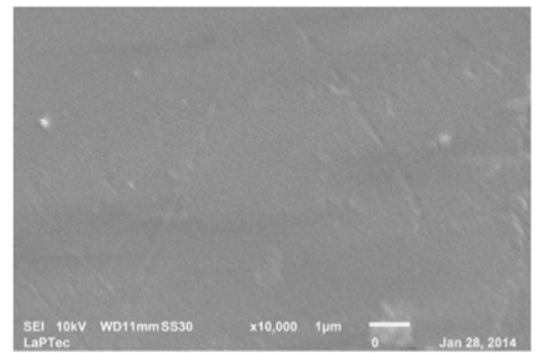

$\mathrm{E}$

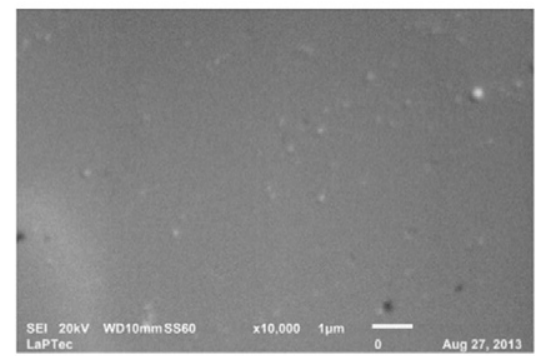

G

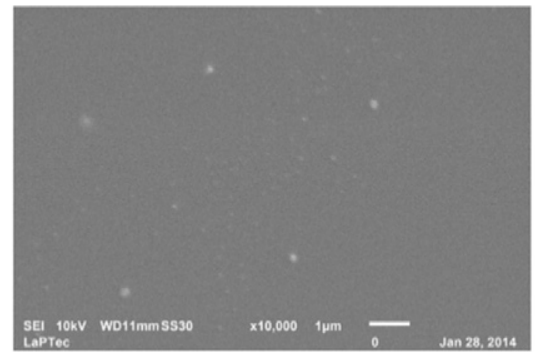

$\mathrm{B}$

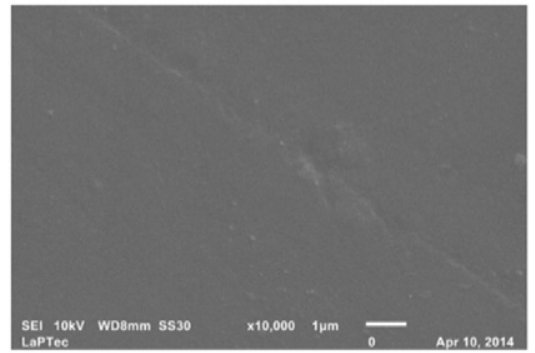

$\mathrm{D}$

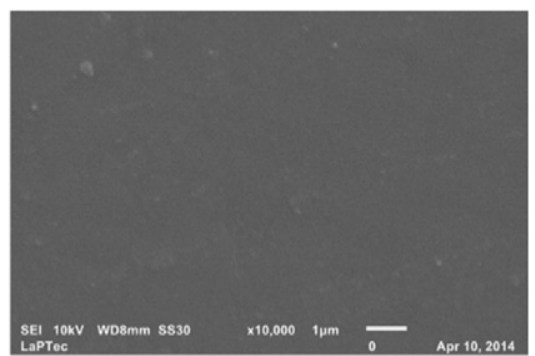

F

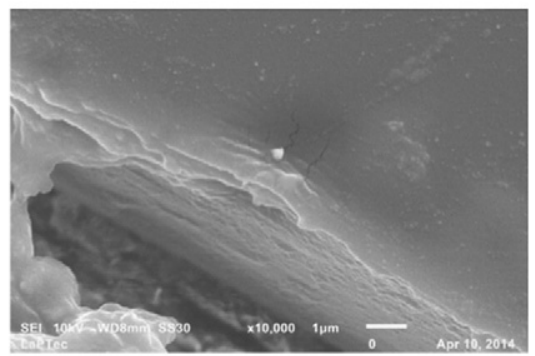

$\mathrm{H}$

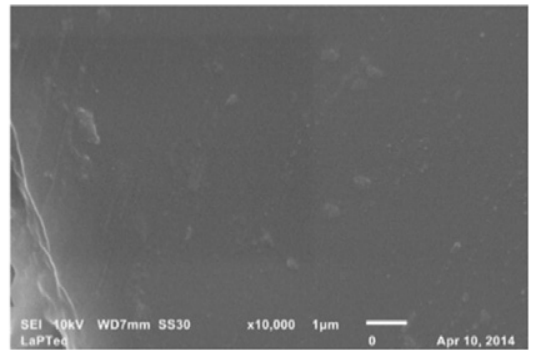

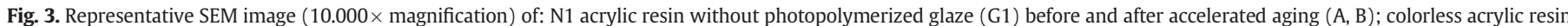

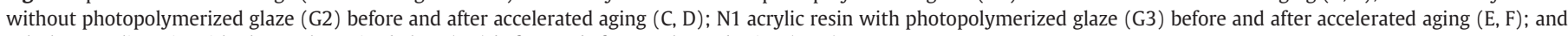
colorless acrylic resin with photopolymerized glaze (G4) before and after accelerated aging $(G, H)$.

Through AFM and SEM images, it can be observed that the topographic characteristics of all groups were not maintained after aging. The surface of groups submitted to chemical polishing had more accentuated peaks and valleys, when compared to groups that received mechanical polishing (Figs. 1 and 3), which corroborates with the results of the roughness analysis. Concerning the wettability, an increase of surface energy was observed after aging (Table 7), regardless of the surface polishing. However, the higher the surface energy, the greater the adhesion, and accumulation of bacterial biofilm [24].

This study has some limitations, such as the use of only one type of chemical polishing for comparison with mechanical polishing (control). Future work can be performed with different chemical polishing agents, aiming to identify surface treatments that optimize the properties of the material. Furthermore, only N1 and colorless resin were tested. However, clinically, resin or oil based pigments [47] may be incorporated to the ocular prosthesis in order to simulate different sclera colors. Therefore, groups with pigments can be tested in future studies.

\section{Conclusion}

The color stability values $(\Delta \mathrm{E})$ were higher in groups with glaze, and these groups had a reduction in microhardness and an increase in roughness after accelerated aging, when compared to groups with mechanical polishing. Therefore, the photopolymerized glaze seems not to be the best option for polishing acrylic resin surfaces used in ocular prostheses, since the color stability, microhardness, and roughness were interfered with negatively after accelerated aging.

\section{Acknowledgments}

The authors thank Elton José de Souza for the Atomic Force Microscopy Analysis performed at the Faculty of Engineering of Ilha Solteira - FEIS/UNESP, Ilha Solteira, Sao Paulo, Brazil. Additionally, the authors thank FAPESP (Foundation for Support to Research of the State of Sao Paulo) for financial support [n. 2013/16642-1] provided to Bruna Egumi Nagay. 

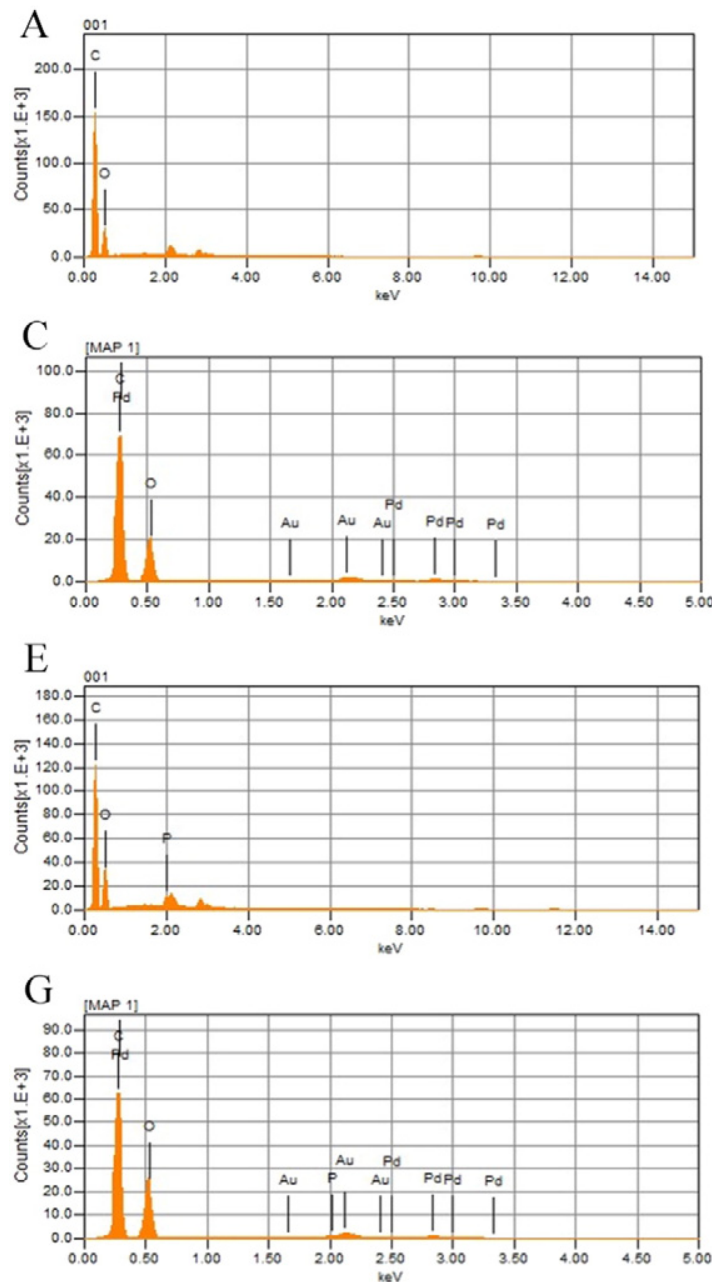

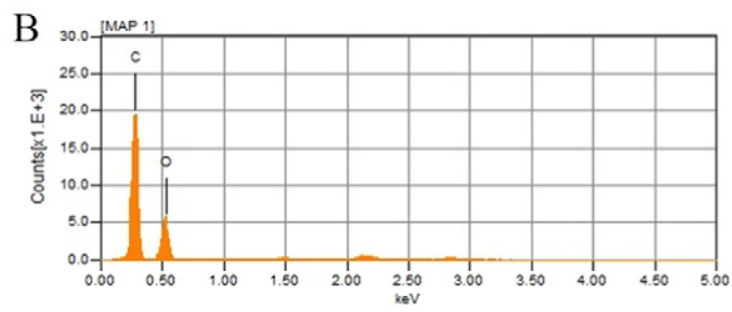

D

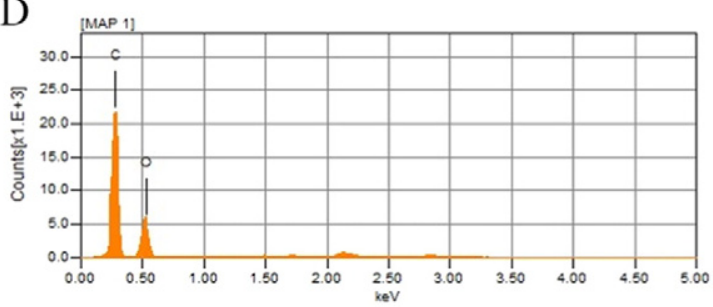

F

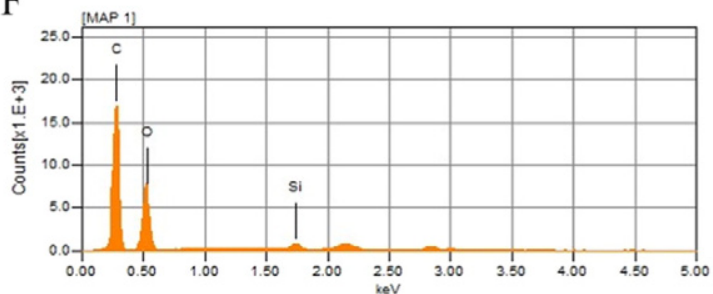

$\mathrm{H}$

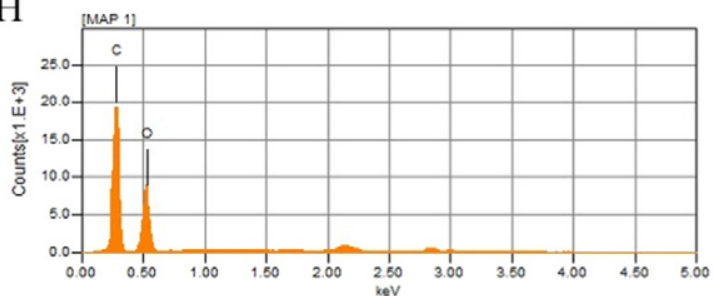

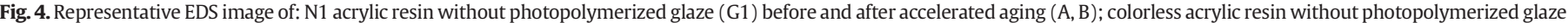

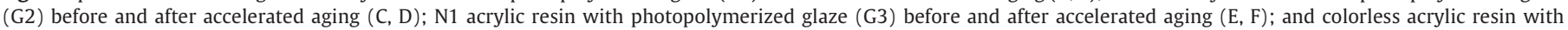
photopolymerized glaze (G4) before and after accelerated aging $(G, H)$.

\section{References}

[1] A.U. Fernandes, M.C. Goiato, D.M. dos Santos, Effect of weathering and thickness on the superficial microhardness of acrylic resin and ocular button, Cont. Lens Anterior Eye 32 (2009) 283-287.

[2] A.U. Fernandes, M.C. Goiato, D.M. Dos Santos, Effect of weathering and thickness on roughness of acrylic resin and ocular button, Cont. Lens Anterior Eye 33 (2010) 124-127.

[3] M.C. Goiato, D.M. Dos Santos, A. Moreno, M.G. Iyda, M.C. Rezende, M.F. Haddad, Effect of disinfection and storage on the flexural strength of ocular prosthetic acrylic resins, Gerodontology 29 (2012) e838-e844.

[4] A. Moreno, M.C. Goiato, D.M. Dos Santos, M.F. Haddad, A.A. Pesqueira, L.C. Bannwart Effect of different disinfectants on the microhardness and roughness of acrylic resins for ocular prosthesis, Gerodontology 30 (2013) 32-39.

[5] L.C. Bannwart, M.C. Goiato, D.M. Santos, A. Moreno, A.A. Pesqueira, M.F. Haddad, et al., Chromatic changes to artificial irises produced using different techniques, J. Biomed. Opt. 18 (2013) 58002.

[6] A.U. Fernandes, A. Portugal, L.R. Veloso, M.C. Goiato, D.M. Santos, Assessment of the flexural strength of two heat-curing acrylic resins for artificial eyes, Braz. Oral Res. 23 (2009) 263-267.

[7] K.A. Schulze, S.J. Marshall, S.A. Gansky, G.W. Marshall, Color stability and hardness in dental composites after accelerated aging, Dent. Mater. 19 (2003) 612-619.

[8] Council On Dental Materials, Instruments and Equipment, Dental Terminology, ANSI/ADA Specification No. 33, American Dental Association, Chicago 1984, p. 14.

[9] K.J. Anusavice, C. Shen, H.R. Rawls, Phillips' Science of Dental Materials, 12th ed. Elsevier, Saint Louis, 2012 474-498.

[10] J.L. Ferracane, Hygroscopic and hydrolytic effects in dental polymer networks, Dent. Mater. 22 (2006) 211-222.
[11] H. Shimizu, M. Kakigi, J. Fujii, F. Tsue, Y. Takahashi, Effect of surface preparation using ethyl acetate on the shear bond strength of repair resin to denture base resin, J. Prosthodont. 17 (2008) 451-455.

[12] J. Marra, R.F. de Souza, D.B. Barbosa, A.C. Pero, M.A. Compagnoni, Evaluation of the bond strength of denture base resins to acrylic resin teeth: effect of thermocycling, J. Prosthodont. 18 (2009) 438-443.

[13] N. Abu-Bakr, L. Han, A. Okamoto, M. Iwaru, Color stability of compomer after immersion in various media, J. Esthet. Dent. 12 (2000) 258-263.

[14] M.C. Goiato, A.A. Pesqueira, D.M. Santos, S.F.C. Dekon, Evaluation of hardness and surface roughness of two maxillofacial silicones following disinfection, Braz. Oral Res. 23 (2009) 49-53.

[15] M.D. Canadas, L.F. Garcia, S. Consani, F.C. Pires-de-Souza, Color stability, surface roughness, and surface porosity of acrylic resins for eye sclera polymerized by different heat sources, J. Prosthodont. 19 (2010) 52-57.

[16] H. Gungel, Scanning electron microscopy and energy dispersive spectroscopy findings in explanted PMMA and hydrophilic acrylic intraocular lenses, Eur. J. Ophthalmol. 19 (2009) 28-36.

[17] M.C. Goiato, D.M. Santos, H.G. Gennari- Filho, A.C. Zavanelli, S.F.C. Dekon, D.N. Mancuso, Influence of investment, disinfection, and storage on the microhardness of ocular resins, J. Prosthodont. 18 (2009) 32-35.

[18] K. Raizada, D. Rani, Ocular prosthesis, Cont. Lens Anterior Eye 30 (2007) 152-162.

[19] A. Carlén, K. Nikdel, A. Wennerberg, K. Holmberg, J. Olsson, Surface characteristics and in vitro biofilm formation on glass ionomer and composite resin, Biomaterials 22 (2001) 481-487.

[20] M. Ikeda, K. Matin, T. Nikaido, R.M. Foxton, J. Tagami, Effect of surface characteristics on adherence of $S$. mutans biofilms to indirect resin composites, Dent. Mater. J. 26 (2007) 915-923.

[21] F. Aykent, I. Yondem, A.G. Ozyesil, S.K. Gunal, M.C. Avunduk, S. Ozkan, Effect of different finishing techniques for restorative materials on surface roughness and bacterial adhesion, J. Prosthet. Dent. 103 (2010) 221-227. 
[22] M.C. Goiato, D.M. Santos, J.F. Souza, A. Moreno, A.A. Pesqueira, Chromatic stability of acrylic resins of artificial eyes submitted to accelerated aging and polishing, J. Appl. Oral Sci. 18 (2010) 641-645.

[23] K.O. Braun, J.A.N. Mello, R.N. Rached, A.A. Del Bel Cury, Surface texture and some properties of acrylic resins submitted to chemical polishing, J. Oral Rehabil. 30 (2003) 91-98.

[24] S.B. Haralur, Evaluation of efficiency of manual polishing over autoglazed and overglazed porcelain and its effect on plaque accumulation, J. Adv. Prosthodont. 4 (2012) 179-186.

[25] V. Rutkunas, V. Sabaliauskas, H. Mizutani, Effects of different food colorants and polishing techniques on color stability of provisional prosthetic materials, Dent. Mater. 29 (2010) 167-176.

[26] J.K. Emmanouil, P. Kavouras, T. Kehagias, The effect of photo-activated glazes on the microhardness of acrylic baseplate resins, J. Dent. 30 (2002) 7-10.

[27] D. Atabek, H. Sillelioglu, A. Olmez, The efficiency of a new polishing material: nanotechnology liquid polish, Oper. Dent. 35 (2010) 362-369.

[28] T. Ohkubo, H. Sepehri-Amin, T.T. Sasaki, K. Hono, Multi-scale characterization by FIB-SEM/TEM/3DAP, Microsc. (Oxf) 63 (Suppl. 1) (2014) i6-i7.

[29] M.A. da Silva, A.B. Fardin, R.C. de Vasconcellos, M. Santos Lde, J. Tonholo, J.G. da Silva Jr., et al., Analysis of roughness and surface hardness of a dental composite using atomic force microscopy and microhardness testing, Microsc. Microanal. 17 (2011) 446-451.

[30] D.R. Monteiro, L.F. Gorup, A.S. Takamiya, E.R. de Camargo, A.C. Filho, D.B. Barbosa, Silver distribution and release from an antimicrobial denture base resin containing silver colloidal nanoparticles, J. Prosthodont. 21 (2012) 7-15.

[31] M.C. Goiato, D.M. Santos, M.F. Haddad, A.A. Pesqueira, Effect of accelerated aging on the microhardness and color stability of flexible resins for dentures, Braz. Oral Res. 24 (2010) 114-119.

[32] CIE (Commission Internationale de l'Eclairage), Colorimetry, third ed. Bureau Central de la CIE, Vienna, 200415.

[33] M.C. Goiato, A. Moreno, D.M. Santos, S.F.C. Dekon, E.P. Pellizzer, A.A. Pesqueira, Effect of polymerization and accelerated aging on iris color stability of ocular prosthesis, Cont. Lens Anterior Eye 33 (2010) 215-218.

[34] ASTM E384 - 11e1 (Standard Test Method for Knoop and Vickers Hardness of Materials), 2012 Available at http://enterprise.astm.org/filtrexx40.cgi?+REDLINE PAGES/E384.htm.

[35] M. Borba, A. Della Bona, D. Cecchetti, Flexural strength and hardness of direct and indirect composites, Braz. Oral Res. 23 (2009) 5-10.

[36] M. Goiato, A.A. Pesqueira, C. Silva, H. Gennari-Filho, D.M. Santos, Patient satisfaction with maxillofacial prosthesis, J. Plast. Reconstr. Aesthet. Surg. 62 (2009) 175-180.

[37] G. Bjerkan, E. Witsø, K. Bergh, Sonication is superior to scraping for retrieval of bacteria in biofilm on titanium and steel surfaces in vitro, Acta Orthop. 80 (2009) 245-250.

[38] A.J. Vechiato Filho, D.M. Dos Santos, M.C. Goiato, R.A. de Medeiros, A. Moreno, L.D. Bonatto, et al., Surface characterization of lithium disilicate ceramic after nonthermal plasma treatment, J. Prosthet. Dent. 112 (2014) 1156-1163.

[39] G.B. Valverde, P.G. Coelho, M.N. Janal, F.C. Lorenzoni, R.M. Carvalho, V.P. Thompson, et al., Surface characterization and bonding of Y-TZP following non-thermal plasma treatment, J. Dent. 41 (2013) 51-59.

[40] ASTM G53 - American Society for Testing Materials G53, West Conshohocken: ASTM 2000 Available at http://www.astm.org/Standards/G53.htm.

[41] F.M. Mundim, P.L. Antunes, A.B. Sousa, L.F. Garcia, F.C. Pires-de-Souza, Influence of artificial accelerated ageing on the colour stability of paints used for ocular prosthesis iris painting, Gerodontology 29 (2012) e312-e317.

[42] P.V.M. Alves, R.M.A. Lima Filho, E. Telles, A. Bolognese, Surface roughness of acrylic resins after different curing and polishing techniques, Angle Orthod. 77 (2007) 528-531.

[43] M.R. Bonatti, T.R. Cunha, R.R. Regis, C.H. Silva-Lovato, H.F.O. Paranhos, R.F. De Souza, The effect of polymerization cycles on color stability of microwave-processed denture base resin, J. Prosthodont. 18 (2009) 432-437.

[44] M.A. Compagnoni, D.B. Barbosa, R.F. De Souza, A.C. Pero, The effect of polymerization cycles on porosity of microwave-processed denture base resins, J. Prosthet. Dent. 91 (2004) 281-285.

[45] A.C. Miéssi, M.C. Goiato, D.M. dos Santos, S.F. Dekon, R.C. Okida, Influence of storage period and effect of different brands of acrylic resin on the dimensional accuracy of the maxillary denture base, Braz. Dent. J. 19 (2008) 204-208.

[46] G.C. Paffenbarger, "Guide to dental materials and devices": a historical review, J. Am. Dent. Assoc. 84 (1972) 1333-1335.

[47] M.C. Goiato, A.Ú. Fernandes, D.M. dos Santos, M.F. Hadadd, A. Moreno, A.A. Pesqueira, Alteration of blue pigment in artificial iris in ocular prosthesis: effect of paint, drying method and artificial aging, Cont. Lens Anterior Eye 34 (2011) 22-25.

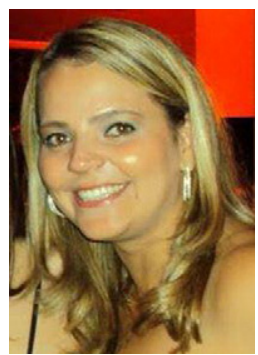

Daniela Micheline dos Santos received her PhD degree from the Araçatuba Dental School, Aracatuba Dental School, Sao Paulo State University (UNESP), Brazil. Currently, she is a professor in the Department of Dental Materials and Prosthodontics at the same university.

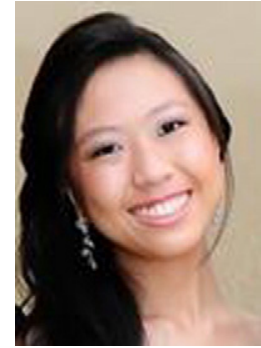

Bruna Egumi Nagay is currently a graduate student at the Araçatuba Dental School, Sao Paulo State University, Brazil.

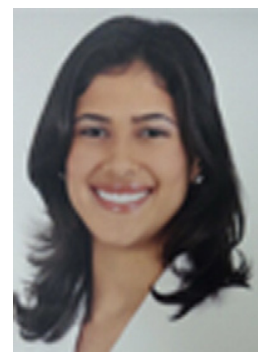

Emily Vivianne Freitas da Silva received her MS degree from the Araçatuba Dental School, Sao Paulo State University, Brazil. Currently, she is a postgraduate student at the same university.

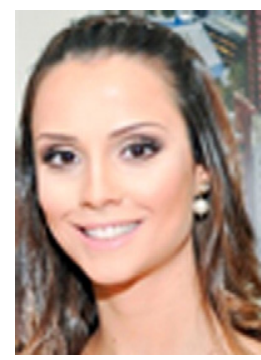

Liliane da Rocha Bonatto received her MS degree from the Araçatuba Dental School, Sao Paulo State University, Brazil. Currently, she is a professor at the Universidade Paranaense (UNIPAR), Brazil.

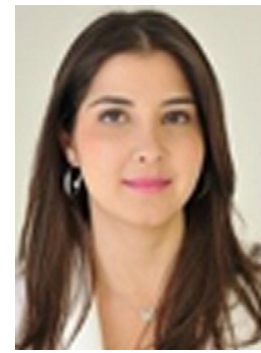

Mariana Vilela Sonego received her MS degree from the Araçatuba Dental School, Sao Paulo State University, Brazil. Currently, she is a postgraduate student at the same university.

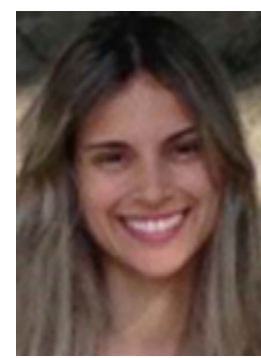

Amália Moreno received her $\mathrm{PhD}$ degree from the Araçatuba Dental School, Sao Paulo State University, Brazil. Currently, she is a professor in the Department of Oral Surgery and Pathology at the School of Dentistry, Federal University of Minas Gerais (UFMG), Brazil.

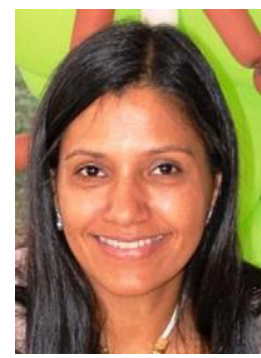

Elidiane Cipriano Rangel received her PhD degree from the Institute of Physics, State University of Campinas, Brazil Currently, she is a professor at the Institute of Science and Technology of Sorocaba, Sao Paulo State University, Brazil. 


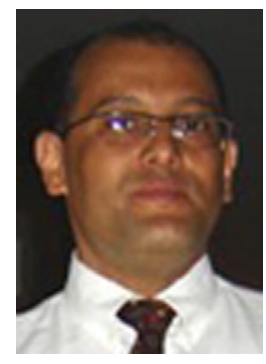

Nilson Cristino da Cruz received his $\mathrm{PhD}$ degree from the Institute of Physics, State University of Campinas, Brazil. Currently, he is a professor at the Institute of Science and Technology of Sorocaba, Sao Paulo State University, Brazil.

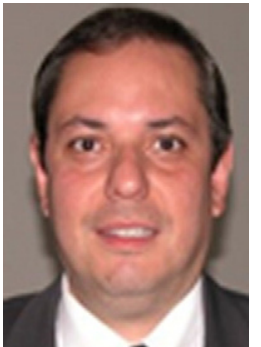

Marcelo Coelho Goiato received his $\mathrm{PhD}$ degree from the Dental School of Piracicaba, State University of Campinas, Brazil. Currently, he is a professor in the Department of Dental Materials and Prosthodontics, Araçatuba Dental School, Sao Paulo State University, Brazil. 